International Journal of Linguistics, Literature and Translation

ISSN: 2617-0299 (Online); ISSN: 2708-0099 (Print)

DOI: 10.32996/ijltt

Journal Homepage: www.al-kindipublisher.com/index.php/ijllt

\title{
The Enhancement of Face-To-Face Reading Skill at the University of Tabuk Using Internet- Based Reading Activities
}

\author{
Turky E. Alshaikhi 8 (D)
}

Languages and Translation department, Faculty of Education and Arts, The University of Tabuk, Tabuk, Kingdom of Saudi Arabia

$\triangle$ Corresponding Author: Turky E. Alshaikhi, E-mail: Talshaikhi@ut.edu.sa

ARTICLE INFORMATION

Received: July 12, 2021

Accepted: August 20, 2021

Volume: 4

Issue: 8

DOI: $10.32996 /$ ijllt.2021.4.8.18

\section{KEYWORDS}

Teaching Strategies, The

Contribution of University EFL

Students, Engagement, Online

learning, and Face-to-Face

Learning

\section{ABSTRACT}

This study aimed to investigate how far internet-based reading activities can enhance learners' reading skills in face-to-face learning experience at the faculty of education and arts, University of Tabuk in Saudi Arabia, for the Academic Year 2021. This study also examined students' learning preferences, experiences, and participation in traditional and non-traditional classrooms as blended learning has come in vogue at the university due to Covid19 restrictions. This quantitative research consisted of 90 university EFL learners from the faculty of education and arts at Tabuk University. The study employed descriptive statistics to analyze learners' responses. The findings showed that internet-based reading activities and peer moderated discussions could enhance learners' reading skills in the face-to-face EFL classes at the university. Internet-based reading activities also led to greater language output in the other three language skills viz., speaking, listening and writing when these are undertaken in the physical mode. However, gaps exist in their application to student learning preferences and whether they match student preferences for reading activities. Limited literature is existed on following up internet-based reading activities with physical learning in traditional classrooms. A single overarching research question guided this study: How far can the innovative method of internet-based reading enhance learners' reading in face-to-face learning environments. The results proved encouraging drills as the previously challenging reading drills were perceived as engaging by the learners after the brief intervention. However, whether the results are temporal or reliable can only be ascertained with larger samples and varied learning environments.

\section{Introduction}

It is an old notion that reading is an activity that is valuable in itself as it adds a worthy dimension to every individual's personality and engages the reader in critical thinking. Yet, the solemn fact remains that it is seen as a dispensable activity in the second or foreign language classroom. The consequence is that few learners acquire any substantial amount of interest in this essential skill. We call it essential as it gives the status of English, as the most popular international and library language, academic and professional success in the higher echelons of knowledge where learners are more or less autonomous, and their deficiency in reading skills can seriously hamper learners' success. In other words, even in second or foreign language environments, English reading skills will actually be the most useful and enduring skill that ought to acquire. The onus to take the learners from the stage of 'learning to read' to 'reading to learn' lies on the educators. Reading in a foreign language requires the learner to be familiar with L2 phonology, vocabulary, morphology and grammar (Geva, 2006). Research indicates that language-specific orthographic differences and growth of developmental pathways that have to do with reading development are likely to follow different stages in different languages (Geva, 2000).

\begin{tabular}{l|l|l}
$\mathbf{K}$ & $\mathbf{C}$ & AL-KINDI CENTER \\
$\mathbf{R}$ & $\mathbf{D}$ & FOR RESEARCH AN
\end{tabular} R D DEVELOPMENT Your gateway to world-class research

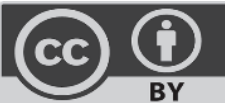

Published by Al-Kindi Center for Research and Development, London, United Kingdom. Copyright (c) the author(s). This open access article is distributed under a Creative Commons Attribution (CC-BY) 4.0 license 
Broadly, three stages are perceptible in the process of reading amongst the university EFL learners in Saudi Arabia. The first of these is 'recognition stage' when the learners merely recognize the graphic form of the language. Being taught as a foreign language, English is introduced at upper primary grades in Saudi Arabia. This pushes the language acquisition stages further ahead for these learners. The second stage is 'interpretation stage' which is only peripherally acquired amongst these learners when they begin to appreciate the idiomatic or nuanced meanings in L2. In fact, achievement of this is not even a stated target of the Saudi curricula, it is only due to the widespread use of internet and smart apps which are highly popular with the young people that is a part of this is autonomously achieved by the learners. The last stage, and one which is rarely achieved in the Saudi EFL scenario is the 'structural stage' when the learners move towards the attainment of mastery in English. It is important to note that the administration encourages the student community to enhance their English skills by offering a large number of study sponsorships under the Study Abroad programs for which a pre-requisite is proficiency in English as the English-speaking countries are very popular amongst the students for higher education. Excellent reading skills under literacy skills and speaking under oral skills are thus highly desirable for academic success.

In any discussion on internet-based reading, one needs to consider the fact that the populations of the world in general, and the learner community in particular, access the internet many times in a day to seek information, establish communication or simply for entertainment. Since almost all of this content is available in English, some degree of facility with technology and language is already prevalent even amongst the EFL learner base. With Covid19 restrictions imposed on college campuses, now more than ever, students should be connecting to the internet for all learning materials.

College instructors may incorporate a variety of teaching strategies in traditional and online classrooms. Various teaching approaches are essential for reaching every student in the school including involving students in events that promote student engagement and collaboration and ultimately improve student learning outcomes (Cuthrell \& Lyon, 2007).

The instructional methods used in the conventional face-to-face classroom are sometimes different from those used in the distance learning environment, where learners will often feel frustrated by the sense of isolation they experience being away from their teacher (Ko \& Rossen, 2010). If a teacher lectures face-to-face or online, their techniques are essential to stimulate student engagement in learning and engage students effectively in learning materials. Understanding how an instructor facilitates learning outcomes in both classroom environments through increasing student participation shows how they can bring about similar successful learning outcomes.

\subsection{Research Objectives}

The objective of this study was to inquire how far internet-based reading methods contribute to enhancing learners' reading skills in face-to-face learning environments. The idea is to make the learners autonomous readers by using internet resources since part of the learning process is still in the online mode in many countries all over the world, and use this autonomy in physical learning in the long run.

\subsection{Research Questions}

The study is centred around a single point of inquiry: How does internet-based reading contribute towards face-to-face reading proficiency of EFL undergraduates in Saudi Arabia?

\section{Review of Literature}

Amid curriculum changes, Chiu et al. (2010) suggested that online learning environments could offer more significant opportunities for elementary faculty to educate learners on how to best draw on their academic strengths. The same researchers have suggested that involvement in IBC usage could provide primary faculty with expanded opportunities to help learners address academic vulnerabilities through differentiated Internet-based learning programs. (Cho et al., 2010). Bennet et al. (2015) examined the relationship between instructional design and student achievement; the findings indicated interactive technology must be strategically selected to improve student learning outcomes. Clark and Mayer (2016) discussed online programs' design to enhance problem-solving and critical thinking skills, focusing on business training. The authors found that online teaching is a useful tool for developing critical thinking skills, and blended learning offers an outlet for dialogue in F2F courses, which further improves learning outcomes. When transitioning to blended learning, the quality of the technology matters, but rather the quality of the teacher's implementation thereof in the classroom (Mudau, 2013).

Transition to IBC needs to commence in elementary grades by equipping students to effectively utilize online learning in later grades. Transition to IBC provides better-differentiated instruction and assessment based on an in-depth understanding of IBC by educational leaders. School officials are reviewing data on the application of Internet-based programs as part of a reform initiative. Additionally, they provide faculty opportunities by developing various forms of authentic assessment to address instructional challenges, supporting students at different levels in two areas of concern to educators who concentrate on implementing IBC (Bawa, 2015; Van Ark, 2012). Continuing research on the IBC subject could promote more understanding and 
encourage the creation of quality measures for Internet-based curriculum use by releasing empirical analysis explorations on the Internet-based curriculum's overall efficacy (González-Marcos, Alba-Elías, Navaridas-Nalda, \& OrdieresMeré, 2016; Karpinski, D'Agostino, Williams, Highland, \& Mellott, 2018).

Many online courses have a higher dropout rate than traditional face-to-face methods (Bawa, 2016; Christensen \& Spackman, 2017; Patterson \& McFadden, 2009). Maintaining active student engagement in online course learning activities (Lee, Pate, \& Cozart, 2015; Bennett \& Monds, 2008) and helping students build self-regulatory skills can reduce online course dropout rates and help more students complete their online courses (Lee et al., 2015; Lee \& Choi, 2011; Muilenburg \& Berge, 2005; Song, Singleton, Hill, \& Koh 2004). Chih-Yuan Sun and Rueda (2012) found that students with higher self-regulation ratings would be more engaged in online learning, suggesting that self-regulation is strongly associated with student participation in the online classroom. Student engagement and investment in learning opportunities are essential in online classes because they can enhance learning outcomes and reduce dropout risks (Finn \& Zimmer, 2012; Lee et al., 2015).

Lee et al. (2015) and Fredricks, Blumenfeld, and Alison (2004) explain that there are three forms of student engagement that are essential to a student's progress in the online environment: behaviorally engaged students who do what is asked of them; cognitively engaged students who can relate information learned from the classroom to their course assignments; and effectively engaged students who are fully immersed in the learning process. Behaviorally engaged students log in to their classes, read the course materials, ask questions, and do what is expected. Cognitive engagement is when students can identify and evaluate new material and then apply that insight appropriately to their course activities and assignments. Fully engaged students are satisfied with their academic successes and are eager to participate in activities. Student engagement in online courses is focused on their motivation level (Lee et al., 2015). A highly motivated student wants to participate in learning activities and become more engaged in the online classroom. Student engagement is a crucial factor influencing a students' decision to either drop out or continue to graduation (Martin \& Bolliger, 2018). Staying actively engaged in the classroom and motivated to learn course content will be necessary for students to develop skills and individual strategies for achieving positive online learning outcomes.

\section{Methods}

This study examined the impact of internet-based reading activities on face-to-face, in-class reading skills enhancement. The participants were 123 undergraduate students from first and second year EFL courses at the University of Tabuk, Saudi Arabia. The median age of the participants fell at 20.6 years, with 68 female and 55 male respondents. All participants affirmed that they had access to an internet connection and computer to carry out the internet-based reading intervention. Learners' reading skills were evaluated at the beginning of the experiment. A five-component rubric was used for this assessment, consisting of the following: i. Decoding by reading words out of context; ii. Phonology or the ability to differentiate between words that similar sound; iii. Semantics by testing how far learners are able to explain the meaning of words, phrases and sentences; iv. Syntax by testing learners' ability to point out incorrect word in a sentence; v. Cipher Knowledge by asking learners to come up with words whose meanings they do not know. Once the intervention ended, and learners resumed their face-to-face reading classes for about two weeks, the rubric was once again used to evaluate if they had benefitted via the internet-based reading training and could successfully transfer the gain to the face-to-face mode of learning. Table 1 in the following section summarizes these comparative values.

\section{Data collection and Analysis}

A total of 123 students from four blended classrooms at University of Tabuk were subjected to a reading skills assessment based on a five-item rubric as discussed in the earlier section. As mentioned, the assessment was administered twice: At the beginning of the study and again two weeks after the intervention was over and learners had resumed face-to-face reading in the classroom setting. For the purposes of the study, only those scores were included that were more than the $50 \%$ mark.

Table1: Reading Assessment Before and After Intervention

\begin{tabular}{|l|l|l|}
\hline & Before & After \\
\hline Decoding & 14 & 39 \\
\hline Phonology & 27 & 63 \\
\hline Semantics & 18 & 56 \\
\hline Syntax & 22 & 35 \\
\hline Cipher knowledge & 9 & 63 \\
\hline
\end{tabular}


The data shows clearly noticeable trends with some parameters reflecting remarkable improvement such as 'decoding' where an improvement of $178 \%$ is perceptible when learners transferred reading skills acquired from internet-based intervention to faceto-face learning. In the post-intervention survey too, respondents reported greater confidence in the ability to read words in isolation. Similar results are seen in the case of 'semantics' where more than $211 \%$ hike with the results corroborated by reverts form the questionnaire wherein respondents variously reported improvements in both receptive and expressive vocabulary which were the areas of highest enhancement, and a better understanding of compound words. Tables 5.6 through table 5.10 include the percentages for the number of students in either face-to-face or online classrooms who provided a specific response to a survey question, out of the total number of students who responded to a question.

Based upon the questionnaire responses, Table 2 below summarizes the percentages of reading enhancement experiences of respondents in face-to-face versus online reading in EFL. Student responses were derived from the total number of students who participated. The questionnaire items sought student response on seven themes, viz. hands on the reading experience, visual impetus, the opportunity for peer discussion/ interaction, availability of examples for reading correctly and coherently, teacher's lectures, group work opportunities, individual reading. Examples of practical activities explained include taking new information and introducing it to another student, focusing on what has been taught, and practicing new ideas. Table 2 below tabulates this data.

Table 2: Responses to Questionnaire Comparing Performance

FEATURE OF READING EXPERIENCE \# INTERNET BASED READING PERFORMANCE \# PERCEIVED
IMPROVEMENT IN FACE-TO-FACE READING
HANDS-ON (32\%) (19\%)
VISUAL (27\%) 8 (26\%)
DISCUSSIONS/INTERACTION (25\%) (23\%)
EXAMPLES (15\%) (23\%)
LECTURES (11\%) (6\%)
GROUP WORK (9\%) (0\%)
READING (4\%) (6\%)
OTHER RESPONSES (52\%) (55\%)

As is evident from the data, respondents indicated their perception of improvements in face-to-face reading as a result of internet-based reading practice claiming that they were pleased with their instructor's teaching style, specifically that they can keep the class engaged, spark conversation, promote learning, and are easy to understand in the new reading method. Some students reported that their teacher effectively communicated and explained information clearly and was eager to help them understand the content. However, some students felt there were areas of their instructor's teaching that could be improved.

Some students mentioned that their instructor was disorganized, did not offer enough hands-on tasks, and should include more visuals when teaching, such as powerpoint presentations or videos. Students in face-to-face courses stated that they need their teacher to present the course content more clearly, that the class was insightful. However, more content needed to be applied, and that the instructor often over-explained the material. Students suggested that while the teacher gave good feedback, the task instructions were vague, that assignments were simple, but they did not retain much of the knowledge and preferred more hands-on practices. Students also indicated an interest in getting clearer communication from their instructors. A total of 87 face-to-face classroom students responded to the survey question, and 48 provided additional responses. Students stated that the instructor encouraged the class to lead the reading process, follow up with discussions, encourage interaction, and support them.

Table 3: respondents' opinions about the reading strategy they most preferred

\begin{tabular}{l}
\hline Specific Learning Activities Preferred \\
\hline Strategy \# of Face-to-Face \# of Online \\
\hline Group Work (27\%) (7\%) \\
\hline No/None (20\%) (0\%) \\
\hline Interactive/Discussion (12\%) (14\%) \\
\hline Hands-on work (8\%) (7\%) \\
\hline Other Responses (55\%) (71\%) \\
\hline
\end{tabular}

Table 3 shows the percentages of face-to-face and online student responses calculated from the number of students providing a listed response out of the total number of students who answered the survey question. Group activities, discussions, and other opportunities that allow students to interact with the rest of the class were commonly listed. Some students preferred more 
group discussions as an opportunity to interact with the class and to participate. Students also indicated that the learning activities currently used in their class met their expectations or already address their learning needs, specifically that the current activities implemented are well structured, examples used were helpful, class discussions assist with understanding the content and that the instructor uses many different activities

A total of 49 students from face-to-face classrooms responded to the question, and 27 of those students provided additional responses. Students mentioned that they would like more assignments, more chances to demonstrate their understanding of course material, more time to take notes, and more extra help. A total of 14 students from online classrooms responded to the question, and each student provided alternative responses to the question and mentioned that they would like more opportunities to ask questions, more discussions that allow for feedback, repetition of learning activities, and more time to review content before taking quizzes. Although there were students from face to face classes who indicated they feel there are no specific learning activities that needed to be included in the class, which represents 20 percent of students from face to face classes in the table, no students from online courses expressly indicated that they were content with the activities implemented in their studies. Each of them listed at least one activity they prefer to be included in the class. It provided detailed descriptions of the instructor participants' profiles, including their teaching background, demographic information, and how their teaching styles are demonstrated as they facilitate their classrooms.

Furthermore, student participants' demographics were provided along with a summary of results from student surveys. This chapter provided themes among participants based on data analysis of eight interviews with college-level undergraduate instructors provided a review of themes and survey results with current literature. Recommendations were provided for strategies used to help students reach the required learning outcome.

This study's overarching research question was: What are teaching strategies used to foster engagement and ensure that students reach the course outcomes by the same teachers in face-to-face and online classroom settings? An additional sub-question was: How have professors identified student's learning needs in their classrooms? The following section discussed how each of the three themes addresses the research question.

The majority of participants used the preferences of students and incorporated them in various areas of course delivery. This approach included providing students with the opportunity to complete their assignments to show their comprehension of the course material and appeal to them directly. Instructors have made class discussions increasingly engaging by relating them to the interests of students. These techniques were used to promote greater engagement in the classroom, encourage students to participate actively, and make further efforts to understand the content introduced.

The findings also provided specific opportunities for increased engagement, motivation, and participation in the classroom. There is literature on students' motivation and performance being influenced by their belief in their ability to do what is required to succeed in class (Chang et al., 2014; Bandura, 1986). This literature also covers the impact of students' self-efficacy on the likelihood of putting forth more effort to complete their assignments and increase their engagement level (Chang et al., 2014; Gist \& Mitchell, 1992; Stajkovic \& Luthans, 1998; Woolfolk, 2001). The current study contributed to the ongoing literature by sharing the participants' perspectives, having implemented various activities to promote interaction. By incorporating what they learned in class in ways specifically relevant to their desires, instructors provide students with the opportunity to complete tasks, ultimately inspiring and encouraging them to become more involved participants in the class. Their willingness to give students the opportunity to complete tasks and assignments that reflect what they want to do provides a clearer understanding of how instructors are taking steps to improve student engagement.

\section{Conclusion}

This study adds to the limited literature on the transference of reading strategies from internet-based to face-to-face mode. This is a valuable addition to the literature, which lacks specific examples of these styles and strategies.

The findings also contribute to further studies into methods of engaging students in the classroom. It outlines examples of students' interests and how they can be integrated into the classroom through a range of activities and assignments, encouraging greater student involvement in the learning process that takes place in the classroom.

The previous literature was limited to some examples of reading strategies aimed at addressing students' individual reading needs in classrooms. Therefore, this research showed that teachers facilitated their classes in ways that students said to help them understand the literature better. Although many students were pleased with the learning methods introduced in their classroom, it was not clear if students were satisfied because the classroom was made more accessible for them to learn best. This study suggests a further analysis of the relationship between strategies used to address student learning preferences and 
student satisfaction and learning outcomes. The information presented in this study contributed to research discussing the strategies used to increase student engagement, address students' preferences for learning, and helping them achieve learning outcomes. These findings should also inform instructors as they develop new ways to facilitate their classrooms to ensure that students are engaged in the information being delivered and are achieving the required learning outcomes for a college course.

\section{References}

[1] Archambault, L., Wetzel, K., Foulger, T. S., \& Williams, M. (2010). Professional and future research. Educational Technology Research and Development, 59(5), 593-187. doi:10.1016/j.compedu.2016.08.005 205-222.618

[2] Bennett, C. F., \& Monds, K. E. (2008). Online courses the real challenge is "motivation." Journal of Digital Learning in Teacher Education, 27(1), 4-11.

[3] Cho, M., \& Shen, D. (2013). Self-regulation in online learning. Distance Education, 34(3), 290-30.

[4] Christensen, S. S., \& Spackman, J. S. (2017). Dropout rates, student momentum, and course. College Teaching Methods \& Styles Journal, 4(6), 1-6.

[5] González-Marcos, A., Alba-Elías, F., Navaridas-Nalda, F., \& Ordieres-Meré, J. (2016).

[6] Finn, J. D., \& Zimmer, K. S. (2012). Student engagement: What is it? Why does it matter? In S. Student evaluation of a virtual experience for project management learning: An

[7] time than face-to-face? International Review of Research in Open and Distance

[8] tools.

[9] Geva E, Siegel LS. Orthographic and cognitive factors in the concurrent development of basic reading skills in two languages. Reading and Writing: An Interdisciplinary Journal 2000;12(1-2):1-30.

[10] Geva, E. (2006). Learning to read in a second language: Research, implications, and recommendations for services. Encyclopedia of Early Childhood Development. https://www.child-encyclopedia.com/second-language/according-experts/learning-read-second-languageresearch-implications-and

[11] L. Christenson, A. L. Reschly \& C. Wylie (Eds.), Handbook of research on student

[12] Learning, 13(3), 132-146.

[13] Lee, E., Pate, J., \& Cozart, D. (2015). Autonomy support for online students. Techtrends:

[14] development 2.0: Transforming teacher education pedagogy with 21st century

[15] empirical study for learning improvement. Computers \& Education, 102(1), 172-

[16] engagement. (pp. 97-131). New York, NY: Springer

[17] Lee, Y., \& Choi, J. (2011). A review of online course dropout research: Implications for practice Linking Research \& Practice to Improve Learning, 59(4), 54-61.

[18] Martin, F., \& Bolliger, D. (2018). Engagement matters: Student perceptions on the importance of engagement strategies in the online learning environment. Online Learning, 22(1),

[19] Mudau, A. V. (2013). A conceptual framework for analyzing teaching difficulties in the

[20] science classroom. Mediterranean Journal of Social Sciences, 4(13), 125-131.

[21] Van de Vord, R., \& Pogue, K. (2012). Teaching time investment: Does online really take more Walls: A New Tool for Distance Education Designers. Journal of Educators. Online, 14(2), 1-16. 